\title{
Evolution of defences in large tropical plant genera: perspectives for exploring insect diversity in a tri- trophic context
}

\author{
by Volf, M., Salmninen J-H. and Segar, S.T.
}

Copyright, Publisher and Additional Information: This is the author accepted manuscript. The final published version (version of record) is available online via Elsevier.

This version is made available under the CC-BY-ND-NC licence:

https://creativecommons.org/licenses/by-nc-nd/4.0/legalcode

Please refer to any applicable terms of use of the publisher

DOI: https://doi.org/10.1016/j.cois.2018.12.005

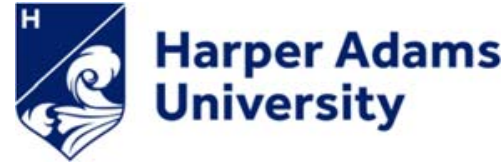

Volf, M., Salmninen J-H. and Segar, S.T. 2018. Evolution of defences in large tropical plant genera: perspectives for exploring insect diversity in a tri-trophic context. Current Opinion in Insect Science. 


\section{Accepted Manuscript}

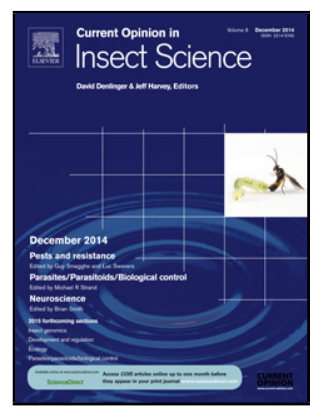

Title: Evolution of defences in large tropical plant genera: perspectives for exploring insect diversity in a tri-trophic context

Authors: Martin Volf, Juha-Pekka Salminen, Simon T. Segar

PII:

S2214-5745(18)30057-9

DOI: https://doi.org/10.1016/j.cois.2018.12.005

Reference: COIS 545

To appear in:

Please cite this article as: Volf M, Salminen J-Pekka, Segar ST, Evolution of defences in large tropical plant genera: perspectives for exploring insect diversity in a tri-trophic context, Current Opinion in Insect Science (2018), https://doi.org/10.1016/j.cois.2018.12.005

This is a PDF file of an unedited manuscript that has been accepted for publication. As a service to our customers we are providing this early version of the manuscript. The manuscript will undergo copyediting, typesetting, and review of the resulting proof before it is published in its final form. Please note that during the production process errors may be discovered which could affect the content, and all legal disclaimers that apply to the journal pertain. 
Evolution of defences in large tropical plant genera: perspectives for exploring insect diversity in a tri-trophic context

Martin Volf ${ }^{1}$, Juha-Pekka Salminen², Simon T. Segar ${ }^{3,4,5}$

${ }^{1}$ Molecular Interaction Ecology Group, German Centre for Integrative Biodiversity Research (iDiv) Halle-Jena-Leipzig, Leipzig, Germany,

${ }^{2}$ Natural Chemistry Research Group, Department of Chemistry, University of Turku, Turku, Finland

${ }^{3}$ Biology Centre, Czech Academy of Sciences, Ceske Budejovice, Czech Republic,

${ }^{4}$ Faculty of Science, University of South Bohemia, Ceske Budejovice, Czech Republic,

${ }^{5}$ Department of Crop and Environment Sciences, Harper Adams University, UK

ORCID:

Martin Volf: 0000-0003-4126-3897

Juha-Pekka Salminen: 0000-0002-2912-7094

Simon T Segar: 0000-0001-6621-9409

*corresponding author: martin.volf@idiv.de 


\section{Graphical Abstract}

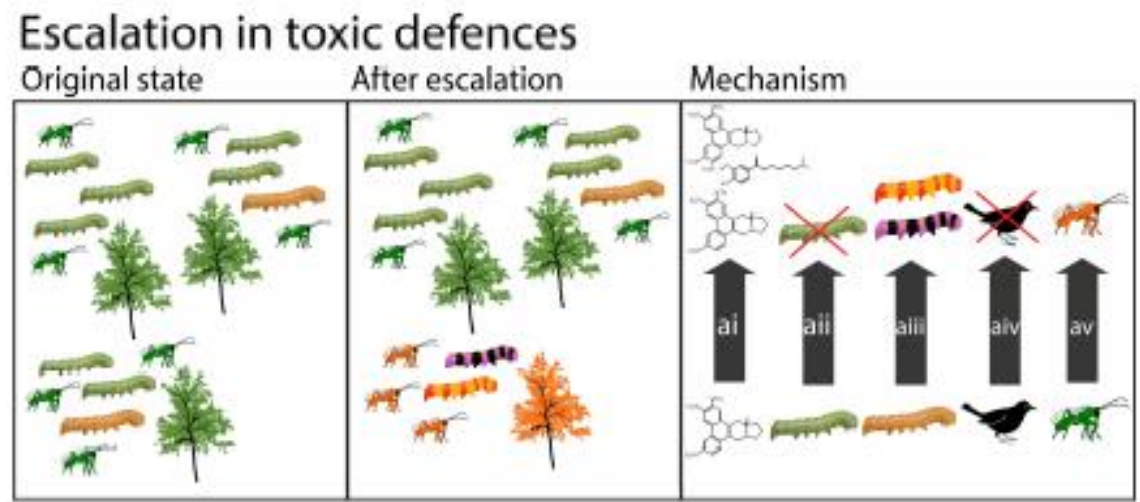

Escalation in less toxic defences

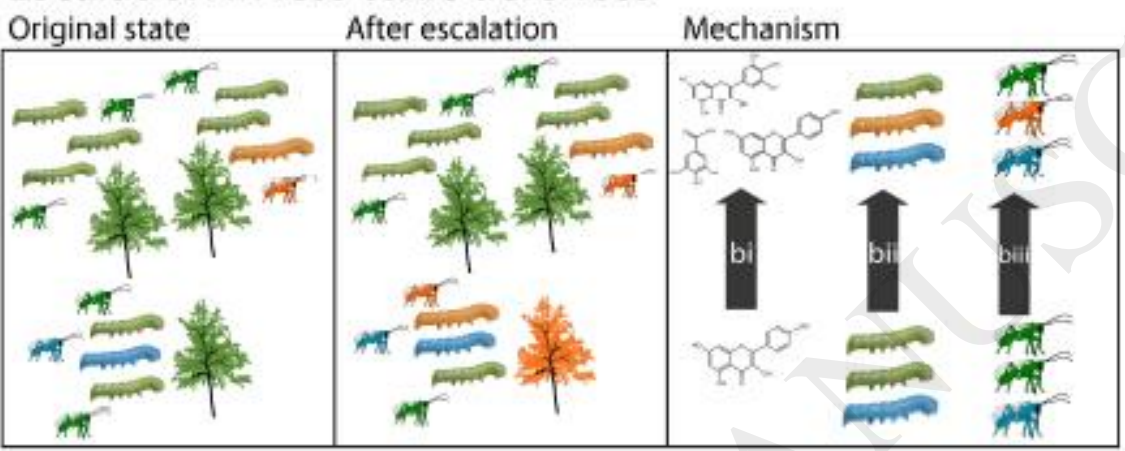

Divergence

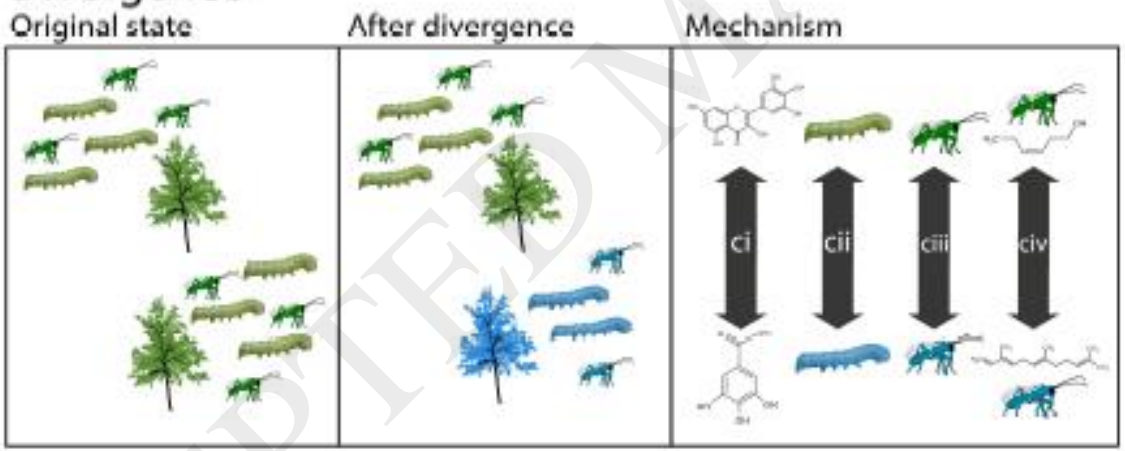

Proposed effects of evolutionary trends in host plant defences on insect diversity. Escalation in toxic defences (ai) frees hosts from herbivory by generalist herbivores (aii). But it can favor speciation of specialized, sequestering herbivores (aiii). The sequestration can lower attractivity of such herbivores to predators (aiv) or disrupts their physiological defences making them preferred by specific parasitoids (av). In contrast, escalation in less toxic defences (bi) probably does not lead to exclusion of herbivores from the community, but rather shifts relative proportion among species, increasing the diversity of herbivores associated with the respective host (bii). This may have a positive cascading effect on parasitoid diversity (biii). A divergence in direct defences (ci) lowers the amount of herbivores the hosts share and promotes herbivore community variation between the hosts (cii). This cascades to parasitoids, promoting variation in their communities as well (ciii). A divergence in HIPVs can further promote the effect (civ). 


\title{
Highlights
}

- Large plant genera harbour a substantial share of the global insect diversity.

- This is because of their chemical diversity, promoted by divergence and escalation.

- This primarily affects the diversity of herbivores and cascades to parasitoids.

- Novel measures of chemical diversity may help to understand the mechanism.

- These need to be combined with detailed herbivore and parasitoids data.

\begin{abstract}
Divergence and escalation in defences promote chemical diversity in plants, and consequently the diversity of insect herbivores. This diversification cascades to insect parasitoids through direct effects on host herbivore susceptibility, changes in herbivore community composition, or disparity in plant volatiles. Large tropical plant genera represent an ideal model for studying these trends due to the high diversity of sympatric species and their insects. Novel measures of chemical structural similarity should be used to analyse evolutionary trends in both direct and indirect defences. Host chemical data need to be combined with detailed herbivore and parasitoid data. This will help to identify truly active compounds. Furthermore, resolved genomic phylogenies for plants and insects should be included to assign directionality in the processes.
\end{abstract}

\section{Key words}

coevolution, divergence, diversification, escalation, herbivory, parasitoids, sequestration 


\section{Introduction}

Large tropical plant genera have long fascinated biologists [1,2]. This is because high abundance and diversity make genera such as Psychotria (ca 1,850 species), Piper (>1,000 species) or Ficus (ca 800 species) a key component of forest communities in both the Paleoand Neotropics $[2,3,4]$. Such large tropical plant genera have been shown to harbour hundreds of insect herbivore species locally and thousands globally [3,5]. Exceptionally high herbivore diversity cascades to higher trophic levels as specialized herbivores sustain parasitoid and predator populations [6].

The diversity of insect communities associated with large tropical plant genera is linked to the chemical diversity of the hosts [e.g. $\left.7^{*}, 8-10^{*}\right]$. The question, "what evolutionary processes have generated chemical diversity in large tropical plant genera?' is thus central to understanding the origin of global insect diversity. Similar evolutionary processes act in other plant genera. But large tropical plant genera (defined as those with >500 species; [11]) represent ideal models as they often include multiple species growing in sympatry that are exposed to the same pool of 
insects. This allows for a comparative framework and direct tests of how trends in host chemistry cascade to other trophic levels and affect their diversity [12].

To date, the evolution of direct constitutive defences (Table 1) has received most attention $\left[7^{*}, 9,10^{*}, 13,14\right]$. Such defences protect plants against herbivores through toxic or deterrent effects. These compounds can be sequestered by specialized herbivores and used as a protection against predators, thus affecting higher trophic levels [15]. But there is a growing body of evidence that evolutionary trajectories of indirect defences and low-molecular-weight volatiles are also crucial for understanding chemical diversity $\left[8,16^{* *}\right]$. Infochemicals (semiochemicals) such as herbivore induced plant volatiles (HIPVs) contribute significantly to plant chemical diversity because their deployment is often species specific [17-19]. Furthermore, indirect induced defences mediate interactions and communication between multiple trophic levels $\left[18^{*}\right]$

Here we identify key evolutionary mechanisms contributing to the diversification of defences in large tropical plant genera, presenting current hypotheses and future directions. Furthermore, we discuss the conceptual and methodological advances necessary for future progress. We highlight the importance of data on associated insect communities, and where possible their phylogenetic relationships, for interpreting these trends.

\section{Evolution of chemical diversity in large tropical plant genera and herbivore diversity}

Recent results illustrate that the evolution of host-plant defences can follow various trajectories including escalation, de-escalation, and divergence (Table 2). Both escalation and divergence of defensive traits may contribute to diversification or variation in host-plant defences, which subsequently affects communities of insect herbivores [e.g. $7^{*}, 10^{*}, 14,20^{*}$ ] (Fig. 1). 
Escalation should promote diversification of plant secondary metabolites over the course of the insect-plant arms-race, increasing the species level $(\alpha)$ diversity of secondary metabolites [21]. In theory, if escalating defences are extremely efficient in providing protection against entire communities of herbivores, selection on other chemical traits could be relaxed, leading to a decline in their diversity. However, empirical evidence suggests that even highly toxic or novel defences seldom provide comprehensive protection against all species and guilds of insects [22]. Individual defensive traits thus often show independent evolution as found in Ficus or Inga $\left[7^{*}, 20^{*}\right]$. Escalation in one trait does not necessarily need to lead to de-escalation in another one. However, negative dependence between the diversity of individual metabolite classes can be still expected in the case of negative dependence in metabolic pathways [23].

Escalation of highly toxic defences can help plants to avoid herbivory by generalists, leaving the community dominated by specialists [7*]. This is likely to decrease the overall diversity of the insect community but can promote the adaptive radiation of specialists [21]. Indeed, there are some examples of species rich and specialized herbivore genera associated with toxic plants [e.g. 24]. In contrast, we hypothesise that less toxic defences (e.g. anti-feedants) may lower the community mean for insect performance and facilitate shifts in insect relative abundance, rather than serve to exclude herbivores from the community (Fig. 1). Increased $\alpha$-diversity of such secondary metabolites may therefore promote insect diversity as found in Ficus, possibly by preventing over-dominance of abundant herbivore species [7*].

But herbivores can adapt to predictable defences, using them as feeding cues [25]. This renders such defences largely inefficient against specialized insects [13,26]. Hosts sharing the respective defensive trait can become susceptible and likely to share their fauna of specialized herbivores. This can either lead to de-escalation in defences or push host communities towards divergence as originally suggested for less diverse genera such as Asclepias or Bursera [13,27]. 
The promotion of $\beta$-diversity in defences among divergent hosts within large tropical plant genera is likely to increase variation in their insect communities [8,28] (Fig. 1). Shared specialized herbivores can be important selection agents in large tropical plant genera such as Psychotria. Congeneric Psychotria species show similar habitat preferences and grow in sympatry [4]. Individual species often share up to 50\% of their herbivores [29]. Under such conditions, divergence in defences can be expected to be a prominent evolutionary trend, and as a consequence it can reduce the overlap of specialized herbivores among sympatric hosts. Indeed, interspecific differences in chemistry of Psychotria species can be of a greater magnitude than intergeneric differences between Psychotria and other plant genera [10*]. Similar divergence has been found in many large tropical plant genera such as Eugenia, Ficus, Piper or locally diverse Inga, promoting chemical $\beta$-diversity between congeners and probably helping them to avoid herbivory $\left[7^{*}, 8,10^{*}, 30\right]$.

The divergence in large tropical plant genera is not limited to direct constitutive defences. The divergence in Piper HIPVs has been shown to reduce herbivore inflicted damage to close relatives, likely by either confounding cues for herbivores or through the recruitment of specialized parasitoids (see Evolution of host-plant defences and its effects on parasitoids below) [8]. Similarly, there is high variation between individual species of Inga not only in their secondary metabolites but also in ant mediated defences [30]. This can potentially further promote the divergence in defensive strategies among closely related Inga species. Similar trends can be expected also in Macaranga that includes many sympatric species which employ various levels of chemical and ant based defences [31]. Both Inga and Macaranga include “only" around 300 species but form locally diverse assemblages, forming an important source for insects similar to large tropical genera.

\section{Evolution of host-plant defences and its effects on parasitoids}


The effects of plant chemical diversity cascade to parasitoids. For example, Piper chemical diversity shapes both caterpillar and parasitic wasp community composition [32*]. This is due to i) the effects of host chemical profile on the susceptibility of herbivores to parasitoids, ii) effects mediated by the changes in herbivore community structure and iii) direct effects of divergence in volatile cues, such as HIPVs (Fig. 1).

First, the chemical composition of an herbivore's diet can directly cascade to parasitoids [33**]. Such cascading effects may be especially strong in the case of the highly specialized communities associated with hosts possessing escalated toxic defences (Fig. 1). Highly specialized herbivores can often sequester host plant metabolites [e.g. 34,35]. Sequestration can protect herbivores from vertebrate predators or disrupt their anti-parasitoid physiological defences, such as melanisation. This can make sequestering herbivores more attractive to insect parasitoids $[15,36]$. Recent evidence suggests that the resulting effects of host-plant chemical profiles cascading to the third trophic level may show relatively wide geographic variation. For example, higher chemical diversity of Piper hosts can facilitate both increased and decreased herbivore resistance to parasitoids [33**]. The studies in Piper should be matched by a similar effort in other large tropical plant genera. This may help to further reveal how the interplay of host chemical diversity and herbivore susceptibility to parasitoids is modulated by the lifehistory of particular species and geographic variation in biotic and abiotic conditions $[32 *, 33 * *]$.

Second, hosts with divergent defences, escalated toxic defences, or escalated anti-feedant defences harbour distinct herbivore communities as outlined above [7*]. As many insect parasitoids show relatively high levels of specialization [37], the effects of evolutionary trends in direct constitutive defences can cascade to the third trophic level and promote variation in parasitoid communities as well (Fig. 1). 
Third, divergence in indirect induced defences, such as HIPVs, between closely related hosts could allow for recruitment of specific parasitoids. This may further promote variation in parasitoid communities between hosts. The evidence for such patterns is still scarce, although they potentially still play a crucial role [32*]. But we can draw on well-studied pollinator-plant interactions. For example, divergence in volatiles seems to be an important source of variation in pollinating wasp communities in Ficus [38]. Host plant volatiles also play a central role in determining pollinator-parasitoid interactions in this system [39]. The scope of current ecoevolutionary studies should be extended to other forms of plant defence in order to examine the effects of their evolution on insect diversity in a tri-trophic context [40]. Methods relying on passive volatile sampling can help considerably here [e.g. 41,42]. They represent an excellent alternative to active sampling methods when exploring volatile profiles in remote tropical regions. These methods mitigate the difficulties associated with transport and electrical supply and allow researchers to run a larger numbers of replicates, as they drastically reduce material costs [41].

\section{Measuring plant chemical diversity has its own pitfalls}

Central to interpreting the interplay between evolutionary trends in plant chemical diversity and insect communities are untargeted metabolomic methods $\left[9,43^{*}\right]$. These approaches couple separation and detection methods such as liquid chromatography (LC) with mass spectrometry (MS), or use nuclear magnetic resonance (NMR) spectroscopy without the prior separation of the compounds. The LC-MS approach, for instance, enables structural comparisons among large sets of unknown compounds, computing their structural similarity matrices that are superior to simple diversity measures such as Shannon diversity [43*].

However, it should be noted that all analytical methods have limits in terms of the breadth of compound detection. Metabolomic analyses typically do not optimise extraction on a compound 
group basis, and this may affect both the composition and concentration of detected compounds. For instance, the choice of the extraction solvent alone may cause up to a 10-fold difference in the content of individual metabolites detected [44]. In terms of detection, NMR is more efficient than MS in detecting all types of major metabolites present in the plant extract, while MS is more sensitive and thus more suitable for detecting compounds present in low concentrations. The LC separation of the hundreds of compounds in plant extracts also favours LC-MS over NMR. However, the typical MS metabolomics methods cannot detect (and/or extract) large metabolites such as polymeric tannins. These need a separate analysis protocol that uses UPLCQqQ-MS/MS for targeted multiple reaction monitoring analysis of four types of tannin groups together with untargeted full scan analysis that allows the detection of many individual tannins $[45,46]$. To conclude, it is important to always recognise that any single method is not perfect and cannot detect and quantify all defence compounds. In these cases, the quantification of biologically relevant bioactivities may yield another level of information that metabolomics tools miss [e.g. $7 *, 47]$.

\section{Linking plant chemical diversity to insect data}

Integrating detailed insect community data can help to interpret complex metabolomics data sets. First, obtaining data on herbivores naturally associated with the focal plant lineage allows us to select candidate herbivores for informed manipulative experiments and feeding trials. Indeed, such tests are needed to reveal how metabolite structures may be linked to their activities [48]. Second, having detailed insect data allows identifying metabolites linked to insect community structure. This is key for interpreting evolutionary trends in plant defences since the production of secondary metabolites can be subject to different degrees of selection depending on their function [16**]. Statistical learning regularization techniques, such as 
LASSO [49], which can handle complex data can be of great help in identifying the metabolites most strongly involved in the insect-plant interactions [16**].

While we begin to understand the distribution of traits between congeneric hosts and better estimate herbivore pressure [8-10*], herbivore and parasitoid communities remain largely unexplored. So far, many studies have focused on a limited number of insect taxa and guilds, especially caterpillars, and in a bi-trophic context only [e.g. $7^{*}, 20^{*}$ ]. This is largely due to the expertise and time needed for the identification of insects in the tropics where delimiting species boundaries is a difficult task. However, a recent renaissance of taxonomy facilitated by DNA barcoding allows us to link refined species to community ecology [50]. Beyond barcoding, molecular data are needed for the robust and informative evolutionary reconstructions central to phylogenetic comparative methods.

A traditional shortcoming has been the relative shortage of statistical methods available for analysing quantitative multivariate community data in a phylogenetic context. But excellent progress is being made in this direction [51,52]. Following these authors, we urge for a tighter inclusion of matched plant and insect community phylogenies that can help understand the evolution of host use and phylogenetic constraints, and to some extent discriminate between higher level macro-evolutionary processes, assigning directionality. For example, densely sampled and well resolved genomic phylogenies of entire insect and plant clades are needed to estimate ancestral plant traits and levels of insect host shifting as well as to provide the context under which plants evolved. Dated phylogenies are particularly relevant here, helping to examine the role of insects themselves in generating chemical diversity and the potential for sequential radiation of insects across plants and cyclical evolutionary dynamics. Large genera with contrasting ages of divergence, such as Ficus (ca 75 MYA) or Inga (ca 2-10 MYA), are ideal models for such comparative studies on the diversification of insects across plants $[7 *, 20 *]$ 


\section{Conclusions}

Overall, we are now in a unique situation when novel methods allow us to explore the evolution of various types of defences and their effects on tri-trophic interactions in large tropical plant genera as never before. These plant genera can indeed serve as model systems for studying the genesis of plant and insect diversity - their herbivores can represent up to $30 \%$ of local fauna in the case of some herbivore lineages [47]. Studies from individual plants systems have so far excelled in individual aspects: for example in metabolomics, in insect community ecology or in providing the evolutionary context [e.g. $\left.7^{*}, 8-10^{*}, 20^{*}, 30\right]$. Increasingly available metabolomics and genomics methods call for a synthesis and synchronization across all these systems and various geographic regions.

\section{Acknowledgements}

MV acknowledges funding by Alexander von Humboldt Foundation and the Federal Ministry for Education and Research. STS was funded by GACR grant 15-24571S. We thank Alexander Weinhold, the referees, and Genoveva Rodriguez-Castaneda for their helpful comments, which improved our manuscript.

\section{References}

1. Corner EJH: Taxonomic notes on Ficus Linn., Asia and Australasia: Addendum. Gardens’ Bulletin Singapore 1961, 18:83-99.

2. Gentry AH: Neotropical floristic diversity: phytogeographical connections between Central and South America, Pleistocene climatic fluctuations, or an accident of the Andean orogeny? Annals of the Missouri Botanical Garden 1982, 69:557-593. 
3. Basset Y, Novotny V, Weiblen G: Ficus: a resource for arthropods in the tropics, with particular reference to New Guinea. In Forests and Insects. Edited by Watt DA, Stork NE, Hunter MD: Chapman \& Hall; 1997:341-361.

4. Sedio BE, Wright SJ, Dick CW: Trait evolution and the coexistence of a species swarm in the tropical forest understorey. Journal of Ecology 2012, 100:1183-1193.

5. Novotny V, Miller SE, Baje L, Balagawi S, Basset Y, Cizek L, Craft KJ, Dem F, Drew RAI, Hulcr J, et al.: Guild-specific patterns of species richness and host specialization in plant-herbivore food webs from a tropical forest. Journal of Animal Ecology 2010, 79:1193-1203.

6. Connahs H, Rodríguez-Castañeda G, Walters T, Walla T, Dyer L, Miller J: Geographic variation in host-specificity and parasitoid pressure of an herbivore (Geometridae) associated with the tropical genus Piper (Piperaceae). Journal of Insect Science 2009, 9.

7*. Volf M, Segar ST, Miller SE, Isua B, Sisol M, Aubona G, Šimek P, Moos M, Laitila J, Kim $\mathrm{J}$, et al.: Community structure of insect herbivores is driven by conservatism, escalation and divergence of defensive traits in Ficus. Ecology Letters 2018, 21:8392.

This study shows that herbivores with different levels of specialization respond to defensive traits with various evolutionary histories. While generalists were primarily affected by escalating defences, specialists were affected by divergent defences of their Ficus hosts.

8. Salazar D, Jaramillo A, Marquis RJ: The impact of plant chemical diversity on plantherbivore interactions at the community level. Oecologia 2016, 181:1199-1208.

9. Richards LA, Dyer LA, Forister ML, Smilanich AM, Dodson CD, Leonard MD, Jeffrey CS: Phytochemical diversity drives plant-insect community diversity. Proceedings of 
the National Academy of Sciences of the United States of America 2015, 112:1097310978

10*. Sedio BE, Rojas Echeverri JC, Boya P, Cristopher A, Wright SJ: Sources of variation in foliar secondary chemistry in a tropical forest tree community. Ecology 2017, 98:616-623.

Here the authors investigated chemical structural similarity among closely related trees from several speciose tropical genera. They show that differences in secondary chemistry among closely related congeneric species are large relative not only to within- species variation but also to variation between different genera. Such large differences may in turn permit niche segregation among congeneric tree species based on chemical defence.

11. Frodin DG: History and concepts of big plant genera. Taxon 2004, 53:753-776.

12. Lewinsohn TM, Novotny V, Basset Y: Insects on plants: diversity of herbivore assemblages revisited. Annual Review of Ecology, Evolution, and Systematics 2005, 36:597-620.

13. Agrawal AA, Fishbein M: Phylogenetic escalation and decline of plant defense strategies. Proceedings of the National Academy of Sciences of the United States of America 2008, 105:10057-10060.

14. Becerra JX, Noge K, Venable DL: Macroevolutionary chemical escalation in an ancient plant-herbivore arms race. Proceedings of the National Academy of Sciences of the United States of America 2009, 106:18062-18066.

15. Dyer LA: Tropical tritrophic interactions: nasty hosts and ubiquitous cascades. In Tropical Forest Community Ecology. Blackwell Science, Oxford. Edited by Carson W, Schnitzer S: Wiley-Blackwell; 2008:275-293. 
16**. Salazar D, Lokvam J, Mesones I, Vásquez M, Ayarza J, Fine P: Origin and maintenance of chemical diversity in a species-rich tropical tree lineage. Nature Ecology \& Evolution 2018.

This study demonstrates that secondary metabolites with strong effects on insect herbivores tend to show stronger phylogenetic signal and different selection patterns than metabolites with less pronounced roles. Therefore, identifying such compounds is critical to correctly interpret insect-plant evolutionary interactions, as compounds with less pronounced effects can obscure the patterns. The authors also highlight the importance of diffuse coevolution for the genesis of plant chemical diversity.

17. Aljbory Z, Chen MS: Indirect plant defense against insect herbivores: a review. Insect Science 2018, 25:2-23.

18*. Turlings TC, Erb M: Tritrophic Interactions Mediated by Herbivore-Induced Plant Volatiles: Mechanisms, Ecological Relevance, and Application Potential. Annual Review of Entomology 2018, 63.

This review provides the most current and comprehensive summary on the role of HIPVs in tritrophic interactions. The authors provide an overview on the current knowledge on the mechanisms involved in forming and mediating HIPV signals. They discuss ecological roles of HIPVs in both natural and agricultural ecosystems. Furthermore, the authors identify the gaps in our understanding of how the HIPVs and their specificity evolve.

19. Danner H, Desurmont GA, Cristescu SM, Dam NM: Herbivore- induced plant volatiles accurately predict history of coexistence, diet breadth, and feeding mode of herbivores. New Phytologist 2017.

20*. Endara M-J, Coley PD, Ghabash G, Nicholls JA, Dexter KG, Donoso DA, Stone GN, Pennington RT, Kursar TA: Coevolutionary arms race versus host defense chase in 
a tropical herbivore-plant system. Proceedings of the National Academy of Sciences of the United States of America 2017, 114:E7499-E7505.

The authors show that host defences are more important for insect host-use than host phylogeny, especially in recently radiated plant genera, such as Inga. Furthermore, they suggest that plant defences may be more evolutionarily flexible than insect adaptations to their hosts, allowing plants to persist in the arms race with their insect herbivores.

21. Ehrlich PR, Raven PH: Butterflies and plants - a study in coevolution. Evolution 1964, 18:586-608.

22. Volf M, Hrcek J, Julkunen- Tiitto R, Novotny V: To each its own: differential response of specialist and generalist herbivores to plant defence in willows. Journal of Animal Ecology 2015, 84:1123-1132.

23. Agrawal AA, Salminen JP, Fishbein M: Phylogenetic trends in phenolic metabolism of milkweeds (Asclepias): evidence for escalation. Evolution 2008, 63:663-673.

24. Farrell BD: Evolutionary Assembly of the Milkweed Fauna: Cytochrome Oxidase I and the Age of Tetraopes Beetles. Molecular Phylogenetics and Evolution 2001, 18:467-478.

25. Rank NE: Host plant preference based on salicylate chemistry in a willow leaf beetle (Chrysomela aeneicollis). Oecologia 1992, 90:95-101.

26. Volf M, Julkunen- Tiitto R, Hrcek J, Novotny V: Insect herbivores drive the loss of unique chemical defense in willows. Entomologia Experimentalis et Applicata 2015, 156:88-98.

27. Becerra JX: The impact of herbivore-plant coevolution on plant community structure. Proceedings of the National Academy of Sciences of the United States of America 2007, 104:7483-7488. 
28. Becerra JX: On the factors that promote the diversity of herbivorous insects and plants in tropical forests. Proceedings of the National Academy of Sciences of the United States of America 2015, 112:6098-6103.

29. Novotny V, Basset Y, Miller SE, Weiblen GD, Bremer B, Cizek L, Drozd P: Low host specificity of herbivorous insects in a tropical forest. Nature 2002, 416:841-844.

30. Kursar TA, Dexter KG, Lokvam J, Pennington RT, Richardson JE, Weber MG, Murakami ET, Drake C, McGregor R, Coley PD: The evolution of antiherbivore defenses and their contribution to species coexistence in the tropical tree genus Inga. Proceedings of the National Academy of Sciences of the United States of America 2009, 106:18073-18078.

31. Nomura M, Hatada A, Itioka T: Correlation between the leaf turnover rate and antiherbivore defence strategy (balance between ant and non-ant defences) amongst ten species of Macaranga (Euphorbiaceae). Plant Ecology 2011, 212:143-155.

32*. Glassmire AE, Jeffrey CS, Forister ML, Parchman TL, Nice CC, Jahner JP, Wilson JS, Walla TR, Richards LA, Smilanich AM: Intraspecific phytochemical variation shapes community and population structure for specialist caterpillars. New Phytologist 2016, 212:208-219.

This study shows that chemical diversity of Piper hosts lowered caterpillar diversity and promoted diversity of the associated parasitoids. The chemical composition of the hosts was highly affected by elevation. This suggests that abiotic factors may play an important role in modulating the effects of plant chemical diversity in the tri-trophic context.

33**. Slinn HL, Richards LA, Dyer LA, Hurtado PJ, Smilanich AM: Across multiple species, phytochemical diversity and herbivore diet breadth have cascading effects on herbivore immunity and parasitism in a tropical model system. Frontiers in Plant Science 2018, 9:656. 
This study links the chemical diversity in diet of herbivres to their succeptibility to parasitoids. Higher chemical diversity of the hosts significantly affected herbivore immunity and parasitism rates. But the direction of the interaction showed large variability, suggesting that increased chemical diversity can facilitate both increased and decreased herbivore resistance to parasitoids depending on the location and species involved.

34. Petschenka G, Agrawal AA: Milkweed butterfly resistance to plant toxins is linked to sequestration, not coping with a toxic diet. Proceedings of the Royal Society BBiological Sciences 2015, 282:20151865.

35. Pasteels JM, Rowell-Rahier M, Braekman JC, Dupont A: Salicin from host plant as precursor of salicylaldehyde in defensive secretion of Chrysomeline larvae. Physiological Entomology 1983, 8:307-314.

36. Dyer LA, Philbin CS, Ochsenrider KM, Richards LA, Massad TJ, Smilanich AM, Forister ML, Parchman TL, Galland LM, Hurtado PJ: Modern approaches to study plantinsect interactions in chemical ecology. Nature Reviews Chemistry 2018:1.

37. Hrcek J, Miller SE, Whitfield JB, Shima H, Novotny V: Parasitism rate, parasitoid community composition and host specificity on exposed and semi-concealed caterpillars from a tropical rainforest. Oecologia 2013, 173:521-532.

38. Souto- Vilarós D, Proffit M, Buatois B, Rindos M, Sisol M, Kuyaiva T, Isua B, Michalek J, Darwell CT, Hossaert- McKey M: Pollination along an elevational gradient mediated both by floral scent and pollinator compatibility in the fig and fig- wasp mutualism. Journal of Ecology 2018.

39. Proffit M, Schatz B, Borges RM, Hossaert- McKey M: Chemical mediation and niche partitioning in non- pollinating fig- wasp communities. Journal of Animal Ecology 2007, 76:296-303. 
40. Moreira X, Abdala-Roberts L, Rasmann S, Castagneyrol B, Mooney KA: Plant diversity effects on insect herbivores and their natural enemies: current thinking, recent findings, and future directions. Current Opinion in Insect Science 2016, 14:1-7.

41. Kallenbach M, Oh Y, Eilers EJ, Veit D, Baldwin IT, Schuman MC: A robust, simple, high- throughput technique for time- resolved plant volatile analysis in field experiments. The Plant Journal 2014, 78:1060-1072.

42. Chalal M, Winkler JB, Gourrat K, Trouvelot S, Adrian M, Schnitzler J-P, Jamois F, Daire X: Sesquiterpene volatile organic compounds (VOCs) are markers of elicitation by sulfated laminarine in grapevine. Frontiers in Plant Science 2015, 6:350.

43*. Sedio BE: Recent breakthroughs in metabolomics promise to reveal the cryptic chemical traits that mediate plant community composition, character evolution and lineage diversification. New Phytologist 2017, 214:952-958.

The author reviews recent advances in analytical chemistry and bioinformatics, which allow comparing complex biological samples. Such methods are especially useful for analysing large and diverse datasets of tropical plants. In addition, he discusses how implementing new indices allowing for measuring structural complexity can advance our understanding of the role of plant chemical diversity in insect-plant interactions.

44. Salminen J-P, Lempa K: Effects of hydrolysable tannins on a herbivorous insect: fate of individual tannins in insect digestive tract. Chemoecology 2002, 12:203-211.

45. Engström MT, Pälijärvi M, Salminen J-P: Rapid fingerprint analysis of plant extracts for ellagitannins, gallic acid, and quinic acid derivatives and quercetin-, kaempferol- and myricetin-based flavonol glycosides by UPLC-QqQ-MS/MS. Journal of Agricultural and Food Chemistry 2015, 63:4068-4079.

46. Engström MT, Palijarvi M, Fryganas C, Grabber JH, Mueller-Harvey I, Salminen J-P: Rapid qualitative and quantitative analyses of proanthocyanidin oligomers and 
polymers by UPLC-MS/MS. Journal of Agricultural and Food Chemistry 2014, 62:3390-3399.

47. Segar ST, Volf M, Isua B, Sisol M, Redmond CM, Rosati ME, Gewa B, Molem K, Dahl C, Holloway JD: Variably hungry caterpillars: predictive models and foliar chemistry suggest how to eat a rainforest. Proceedings of the Royal Society of London B: Biological Sciences 2017, 284:20171803.

48. Fincher RM, Dyer LA, Dodson CD, Richards JL, Tobler MA, Searcy J, Mather JE, Reid AJ, Rolig JS, Pidcock W: Inter- and intraspecific comparisons of antiherbivore defenses in three species of rainforest understory shrubs. Journal of Chemical Ecology 2008, 34:558-554.

49. Tibshirani R: Regression shrinkage and selection via the lasso. Journal of the Royal Statistical Society. Series B (Methodological) 1996:267-288.

50. Miller SE, Hausmann A, Hallwachs W, Janzen DH: Advancing taxonomy and bioinventories with DNA barcodes. Philosophical Transactions of the Royal Society B 2016, 371:20150339.

51. Ives A, Godfray $\mathrm{H}$ : Phylogenetic analysis of trophic associations. The American Naturalist 2006, 168:E1-E14.

52. Pearse WD, Cadotte MW, Cavender-Bares J, Ives AR, Tucker CM, Walker SC, Helmus MR: Pez: Phylogenetics for the environmental sciences. Bioinformatics 2015, 31:2888-2890.

53. Haak DC, Ballenger BA, Moyle LC: No evidence for phylogenetic constraint on natural defense evolution among wild tomatoes. Ecology 2014, 95:1633-1641.

54. Cacho NI, Kliebenstein DJ, Strauss SY: Macroevolutionary patterns of glucosinolate defense and tests of defense- escalation and resource availability hypotheses. $\mathrm{New}$ Phytologist 2015, 208:915-927. 


\section{Figure captions}

Figure 1. Proposed effects of evolutionary trends in host plant defences on insect diversity. Escalation in toxic defences (ai) frees hosts from herbivory by generalist herbivores (aii). But it can eventually favor speciation of specialized, sequestering herbivores (aiii). The sequestration can lower attractivity of such herbivores to predators (aiv) or disrupts their physiological defences making them preferred by specific parasitoids (av). In contrast, escalation in less toxic defences (bi) probably does not lead to exclusion of herbivores from the community, but rather shifts relative proportion among species. This can increase the diversity of herbivores associated with the respective host (bii) and have a positive cascading effect on parasitoid diversity (biii). A divergence in direct defences (ci) lowers the amount of herbivores the hosts share and promotes herbivore community variation between the hosts (cii). This cascades to parasitoids, promoting variation in their communities as well (ciii). A divergence in HIPVs can further promote the effect (civ). 
Escalation in toxic defences

Original state After escalation
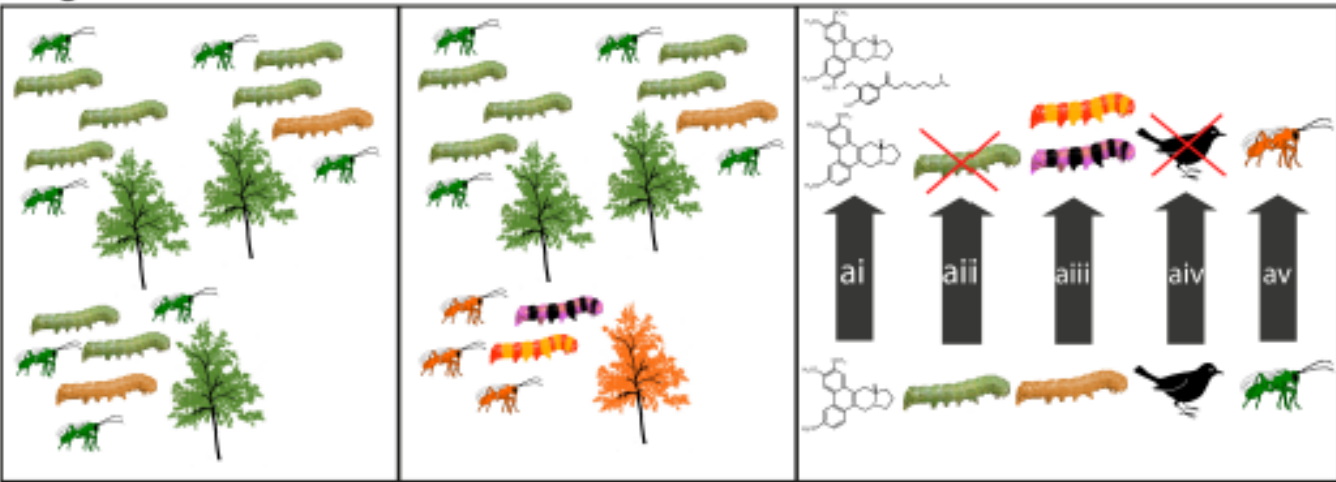

Escalation in less toxic defences

Original state

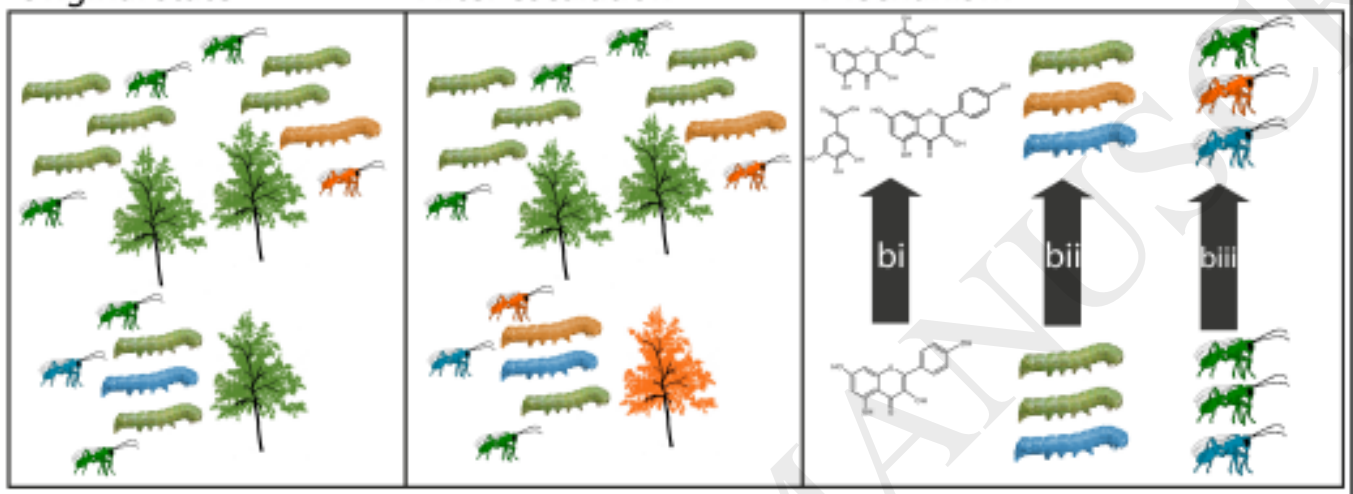

\section{Divergence}

Original state

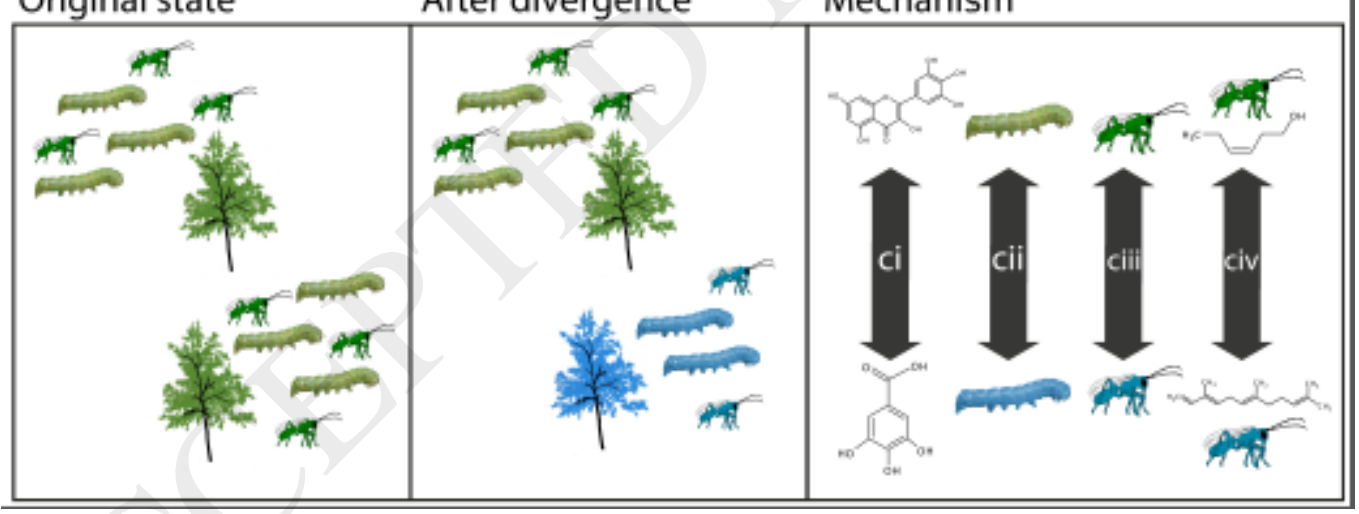




\section{Tables}

Table 1. Used terms and definitions.

\begin{tabular}{|ll|}
\hline Term & Definition \\
\hline Escalation of defences & $\begin{array}{l}\text { Macroevolutionary trend towards higher } \\
\text { concentration, activity, or diversity of host } \\
\text { defences }\end{array}$ \\
\hline De-escalation of defences & $\begin{array}{l}\text { Macroevolutionary trend towards lower } \\
\text { concentration, activity, or diversity of host } \\
\text { defences }\end{array}$ \\
\hline Divergence in defences & $\begin{array}{l}\text { Marcoevolutionary trend towards disparity in } \\
\text { defences between closely related hosts }\end{array}$ \\
\hline Constitutive defences & Defences that are always present in the plant \\
\hline Induced defences & $\begin{array}{l}\text { Defences that change in their expression or } \\
\text { concentration in response to herbivore or } \\
\text { pathogen attack }\end{array}$ \\
\hline Direct defences & $\begin{array}{l}\text { Chemical or physical defences targeted directly } \\
\text { at the herbivore, thereby affecting its } \\
\text { preference of performance. They can be } \\
\text { constitutive and/or inducible. }\end{array}$ \\
\hline Indirect defences & $\begin{array}{l}\text { Chemical defences attracting predators or } \\
\text { parasitoids impacting the herbivores. These } \\
\text { include e.g. herbivore induced plant volatiles } \\
\text { or extrafloral nectaries. They can be } \\
\text { constitutive and/or inducible. }\end{array}$ \\
\hline Targeted metabolomics & $\begin{array}{l}\text { Metabolomics analysis targeted at } \\
\text { identification and quantitation of a defined set } \\
\text { of metabolites. }\end{array}$ \\
\hline $\begin{array}{l}\text { Metabolomics analysis focused on } \\
\text { quantification of overall metabolome profile } \\
\text { and comparing it across samples. }\end{array}$ \\
\hline
\end{tabular}

Table 2. Evolutionary trends in defences recovered in plant genera. Large tropical plant genera with at least 500 species are reported first. Other plant genera in which divergence, escalation, 
or de-escalation was found are reported below the horizontal line. In the case of Protium, the asterisk indicates that while overall chemical profiles showed divergence, compounds with effect on herbivores showed trends towards directional selection. Question marks indicate cases where the presence of a reported trend is likely. Further confirmation requires additional analyses and/or wider sampling effort.

\begin{tabular}{lccccc}
\hline & $\begin{array}{c}\text { Number of } \\
\text { species }\end{array}$ & $\begin{array}{c}\text { Divergence } \\
\text { in defences }\end{array}$ & $\begin{array}{c}\text { Escalation } \\
\text { of defences }\end{array}$ & $\begin{array}{c}\text { De-escalation } \\
\text { of defences }\end{array}$ & References \\
\hline Eugenia & $\sim 1,000$ & $?$ & & {$\left[10^{*}\right]$} \\
Ficus & $\sim 800$ & yes & yes & {$\left[7^{\star}\right]$} \\
Piper & $>1,000$ & yes & & {$[8,9]$} \\
Psychotria & $\sim 1,850$ & yes & & {$\left[10^{*}\right]$} \\
Solanum & $>1500$ & $?$ & & {$[53]$} \\
\hline Asclepias & $>140$ & & yes & {$[13,23]$} \\
Bursera & $\sim 100$ & yes & yes & {$[14,27]$} \\
Inga & $\sim 300$ & yes & & {$\left[20^{*}, 30\right]$} \\
Ocotea & $>300$ & $?$ & & {$\left[10^{*}\right]$} \\
Protium & $\sim 150$ & yes & & {$\left[16^{\star *}\right]$} \\
Salix & $\sim 400$ & & & {$[22,26]$} \\
Streptanthus & $\sim 35$ & & yes & {$[54]$} \\
\hline
\end{tabular}

